\title{
Author Index Volume 14
}

Information technology management in statistical agencies

Arvemo-Notstrand, K. and Olsson, A.-K., Transition to the labour market Session A: immigration and working life

Banovec, T., Republic of Slovenia - records and statistics as basis for the determination of spheres of regions and for calculation of regional accounts

Bethlehem, J., see F. van de Pol

Blom, S., Tracing the integration of refugees in the labour market -

A register approach

Church, J., see Holt, D.

Cornish, J., see Richter, W.

G.W. de Bolster, ECE/CES 1997. The impact of EDI on data collection using EDI for data collection from establishments

Desrosières, A., The administrator and the scientist: how the statistical profession has changed

Everett, G., see Holt, D.

Fang, B., see Han, X.

Garonna, P. and Sofia, F., Statistics and nation-building in European history

Guteland, G. and Malmborg, E., Our legacy to future generations using databases for better availability and documentation

Gilomen, H., Introduction

Han, X. and Fang, B., Measuring the size of tourism and its impact in an economy

Harrison, B.R., Language integration: results of an intergenerational analysis

Hoffmann-Kroll, R., see Seibel, S.

Holt, D., Everett, G. and Church, J., Managing changes to standard geographies in the UK 
Hunter, D., see Skinner, T.J.

Jensen, P., Preparation for the re-use of non-contemporary statistics some Danish experiences, provisions and ideas

Kamen, C.S., The categorization of Jewish ethnicity in Israel

Kenessey, Z., The integration of the statistical profession

Lischer, R., Röthlisberger, P. and Schmid, B., Education and integration in Switzerland - A conflicting picture regarding the situation of foreigners

MacDonald, A.L., Lost and forgotten? Official colonial statistics: experience in constructing historical statistics for Surinam

Malaguerra, C. and Suarez de Miguel, R., Cantonal statistics and federal statistics: process of integration of the statistical system of Switzerland

Malmborg, E., see Guteland, G.

Melkas, J., The principles of selecting material for the internet at Statistics Finland

Mikkelsen, L., Introduction

Nowack, M., The impact of the Internet on statistical organisations

Olsson, A.-K., see Arvemo-Notstrand, K.

Outrata, E., A statistician in transition: differences between an official statistician in a planned economy and in a market one

F. van de Pol and Bethlehem, J., Data editing perspectives

Richter, W. and Cornish, J., Metadata systems to turn numbers into information

Röthlisberger, P., see Lischer, R.

Ryten, J., Blue and white collar statisticians - a gap revisited

Schäfer, D., see Seibel, S.

Schmid, B., see Lischer, R.

Scott, W., Poverty in transition in eastern Europe and the Commonwealth of Independent States: conceptual issues and some findings

Seibel, S., Hoffmann-Kroll, R. and Schäfer, D., Land use and biodiversity indicators from ecological area sampling - results of a pilot study in Germany

Sheshinski, R.H., Environmental information from censuses and surveys 
Skinner, T.J., Hunter, D. and Vaughan, E.P., Developing suitable designators for a multicultural society

Smith, W., Statistics Canada's intranet: a road under construction

Sofia, F., see Garonna, P.

Suarez de Miguel, R., see Malaguerra, C.

Vaughan, E.P., see Skinner, T.J. 